\title{
Influence of shape fabric and crystal texture on marble degradation phenomena: simulations
}

\author{
Victoria Shushakova $\cdot$ Edwin R. Fuller Jr • \\ Siegfried Siegesmund
}

Received: 19 August 2010/Accepted: 11 September 2010/Published online: 28 September 2010

(C) The Author(s) 2010. This article is published with open access at Springerlink.com

\begin{abstract}
Microstructure-based finite element simulations were used to study the influence of grain shape fabric and crystal texture on thermoelastic responses related to marble degradation phenomena. Calcite was used as an illustrative example for studying extremes of shape preferred orientation (SPO) in shape fabric and lattice preferred orientation (LPO) in crystal texture. Three SPOs were analyzed: equiaxed grains, elongated grains, and a mixture of equiaxed and elongated grains. Three LPOs were considered: a random orientation distribution function and two degrees of strong directional crystal texture. Finally, the correlation between the direction of the LPO with respect to that of the SPO was examined. Results show that certain combinations of SPO, LPO, and their directional relationship have significant influence on the thermomechanical behavior of marble. For instance, while there is no major dependence of the elastic strain energy density and the maximum principal stress on SPO for randomly textured microstructures, there is a strong synergy between LPO and its directional relationship with respect to the SPO direction. Microcracking precursors, elastic strain energy density, and maximum principal stress, decrease when the crystalline $c$-axes have fiber texture perpendicular to the SPO direction, but increase significantly when the $c$-axes have fiber texture parallel to the SPO direction. Moreover, the microstructural variability increases dramatically for these latter configurations. In general, the influence of LPO was as expected, namely, the strain energy density and the maximum principal stress decreased with more crystal texture, apart from for the
\end{abstract}

V. Shushakova $(\varangle) \cdot$ E. R. Fuller Jr · S. Siegesmund Geowissenschaftliches Zentrum der Universität Göttingen, Goldschmidtstrasse 3, 37077 Göttingen, Germany e-mail: victoria.shushakova@gmail.com exception noted above. Spatial variations of these precursors indicated regions in the microstructure with a propensity for microcracking. Unexpectedly, important variables were the microstructural standard deviations of the spatial distributions of the microcracking indicators. These microstructural standard deviations were as large as or larger than the variables themselves. The elastic misfitstrain contributions to the coefficients of thermal expansion were also calculated, but their dependence was as expected.

Keywords Shape fabric - Shape preferred orientation Crystal texture - Lattice preferred orientation - Marble . Calcite - Finite element simulations - Thermal expansion anisotropy · Elastic strain energy density · Maximum principal stress - Orientation distribution function . Coefficient of thermal expansion

\section{Introduction}

Marbles have been considered to be among the most important building materials since ancient times. Regarded as special stones, they are captivating because of their pureness, formability, and translucence. However, degradation of sculptures, architectural heritage, and façade stone made from marbles is problematic. Such deterioration of building stones depends mainly on climate. Many experimental studies have shown that temperature changes, both increases and decreases, induce significant deterioration. Even when the temperature changes are not particularly large, repeated heating and cooling of stone will eventually lead to deterioration over time, e.g., Kessler (1919), Battaglia et al. (1993), Winkler (1994), Siegesmund et al. (2000), Zeisig et al. (2002). This deterioration is most spectacular for marbles, but is also observed for 
other rocks, like granite, Nagelfluh, and limestone, e.g., Siegesmund and Dürrast (2011).

The rock-forming minerals in marble, like calcite and dolomite, have large anisotropy in their coefficients of thermal expansion. Hence, apart from the expansion or contraction that results from heating or cooling, residual stresses will develop in the stone due to the thermal expansion anisotropy between the constitutive crystalline grains. These stresses can result in thermally induced microcracking, and an additional concomitant expansion. This behavior is exacerbated by moisture due to moistureassisted subcritical crack growth (Henry et al. 1978; Atkinson 1984), and hence degradation can accumulate with cycling and over time, resulting in significant timedependent deterioration (Koch and Siegesmund 2004).

For some marbles, the degradation process is expressed as a penetrative granular disintegration. This phenomenon is typical for Carrara marbles, although it is not restricted to only this marble type. At the sculpture surfaces a progressive fabric decohesion leads to a sugar-like crumbling of the isolated crystalline grains of calcite, resulting in a progressive deterioration of the stone. An example of this degradation phenomenon is shown in Fig. 1a. The Madonna and Child statue of Carrara marble is generally well preserved due to a thin, hardened outer layer. However, the interior rock fabric has undergone a progressive decohesion along the grain boundaries, resulting in loss of the facial features.

A more spectacular deterioration phenomenon occurs for marble slabs, namely their bowing behavior. Due to progress in natural stone machining, unprecedented creative options are now available for economical cladding with natural stone slabs. This has led to a renaissance in the use of natural stone as a modern building material. Despite the aesthetic gains, there are structural and aesthetic issues. Exposed to the weather, stone claddings may be disaggregated in their structure, and thus irreversibly deformed. The bowing of marble façade slabs, or gravestones (see Fig. 1b), with thicknesses of typically 30 to $40 \mathrm{~mm}$, but occasionally up to $90 \mathrm{~mm}$, have been reported (Grimm 1999; Siegesmund et al. 2008). Both panel thickness and temperature influence the development of bowing (Koch and Siegesmund 2002, 2004; Grelk et al. 2004). Moreover, both convex and concave deformation can occur after only a few years of exposure. This kind of deformation was already described in the literature as early as 1919 by Kessler (1919), and more recently by Sage (1988) and Logan et al. (1993). They found that repeated heating of marble can cause a permanent expansion via damage to the microstructure, and thereby to the cladding. The process behind this phenomena is still under debate. Microstructure-based finite element simulations were used by Weiss et al. (2002, 2003, 2004), Saylor et al. (2007), and Wanner et al. (2010) to provide excellent insight into the influence of crystal texture (lattice preferred orientation) and grainneighbor misorientation configurations on the microstructural strain energy and stresses affecting thermal degradation. The basic observation is that the rock fabric has a significant influence on the residual strains that occur during thermal excursions, thus on thermal degradation.
Fig. 1 Two examples of marble degradation phenomena.

a Madonna and Child statue of Carrara marble on a tombstone in the historic Munich cemetery. The statue is generally well preserved due to a thin, hardened outer layer. However, the interior rock fabric exhibits a progressive granular decohesion along the grain boundaries, the so-called sugaring phenomenon. b A warped gravestone of Carrara marble in the Montmartre Cemetery, Paris, France
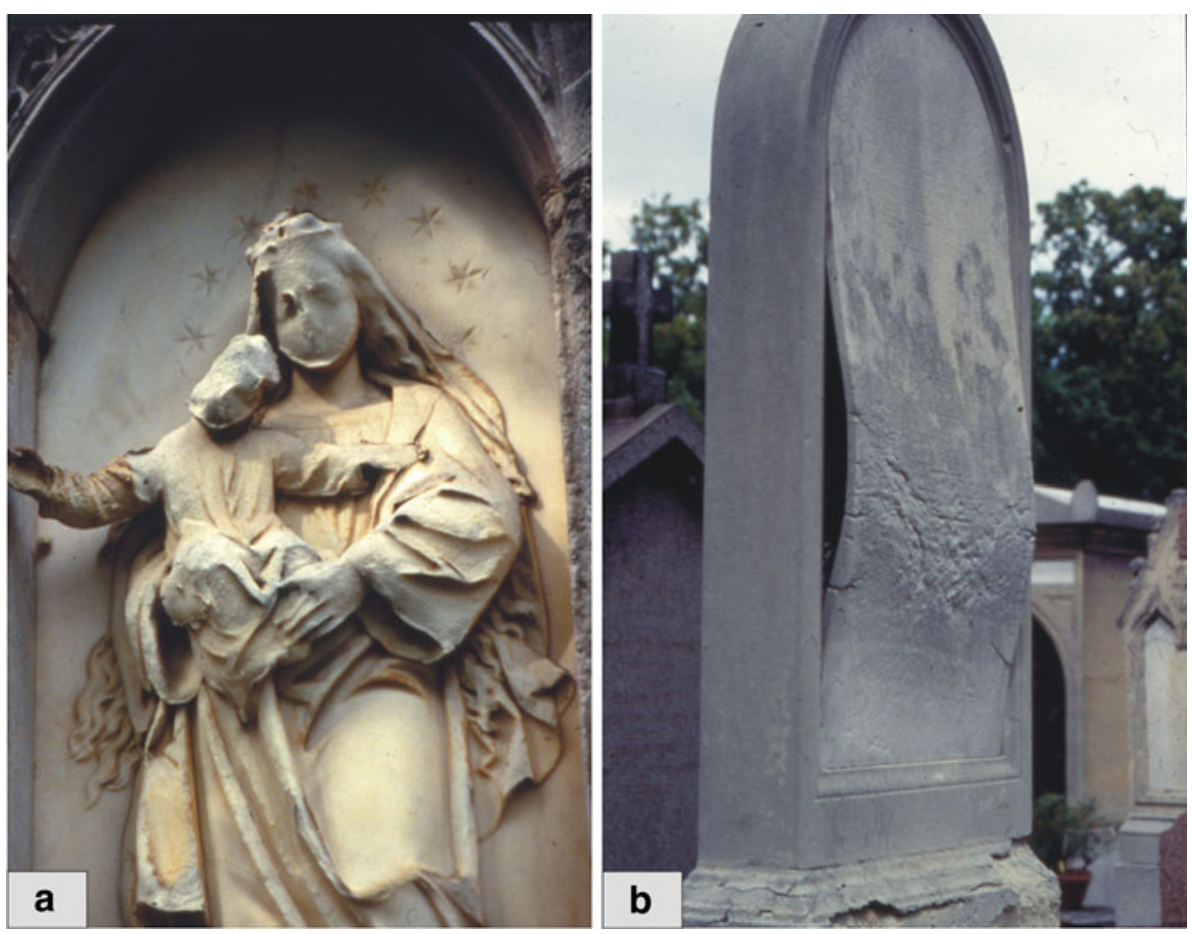
Moreover, the thermal expansion behavior of marbles was modeled with a good coincidence to real experiments. Systematic experimental studies by Zeisig et al. (2002) and Siegesmund et al. (2008) showed that grain size, lattice preferred orientation (LPO), as well as the shape preferred orientation (SPO) can cause a different amount of residual strain. They pointed out that different calcite marbles will have different coefficients of thermal expansion because the size and orientation of the calcite crystalline grains as well as their shape will be different.

The objective of this paper is to elucidate the synergistic influence of shape fabric (e.g., SPO) and crystal texture (e.g., LPO) on factors, such as the stored elastic strain energy density and microstructural stresses, that influence marble degradation. Calcite is used as an illustrative example, but results are expected to be general for myriad marble microstructures, as the thermophysical properties of various marbles do not differ that much. Microstructurebased finite-element simulations are used to explore a wide range of SPO and LPO. We examine the extremes of shape fabric: an equiaxed and an elongated microstructure with an intermediate case that is a mixture of the two extremes, as illustrated in Fig. 2. We also examine extremes of crystal texture from a random orientation distribution function (ODF) to ODFs that are crystallographically textured at 20 and 40 times a random ODF, also as illustrated in Fig. 2. Additionally, the directionality of the LPO with respect to the SPO is examined and is found to have a significant influence.

\section{Microstructural simulations}

\section{Simulation design}

The simulation design matrix has $3 \times 3 \times 3$ or 27 variables. The three SPOs are an equiaxed microstructure, a mixed microstructure, and an elongated microstructure (see Fig. 3). The three LPOs are a random ODF, an ODF with fiber-texture that is 20 times random, and an ODF with fiber-texture that is 40 times random. The last three variables are the directionality of the LPO fiber texture with respect to the SPO. These directional conditions are crystal fiber texture perpendicular to the SPO, but in the plane of the microstructure; crystal fiber texture parallel to the SPO; and crystal fiber texture perpendicular to the SPO, but out of the plane of the microstructure. For the random ODF these three directional conditions are equivalent and are not distinct. Accordingly, there are only 21 unique configurations specified by shape fabric, crystal texture, and directionality of the LPO with respect to the SPO. For each of these 21 cases five different, independent sets of orientations, or replications, were generated. Thus, 105 microstructural configurations served as the basis for the finite-element simulations.

Shape fabric

The two-dimensional simulated rock microstructures were generated by a nucleation and growth algorithm, which is described in detail elsewhere (Ito and Fuller 1993; Miodownik et al. 1999; Saylor et al. 2004, 2007). Circular or elliptical seeds were used to give the extremes in shape fabric. For circular (isotropic) seeds the simulated equiaxed microstructure is a Voronoi tessellation (see Fig. 3a). For elongated elliptical seeds the simulated microstructure is elongated. By giving directionality to the seeds, in this case along the $y$-axis, the textured shape fabric (or SPO) shown in Fig. 3c is obtained. Using a mixture of the two types of seeds, the mixed shape fabric shown in Fig. 3b is obtained.

The microstructural images have a resolution of $1,000 \times 1,000$ pixels. The number of grains in the equiaxed, mixed, and elongated microstructures, respectively, are 382 grains, 347 grains, and 312 grains. Accordingly, the average grain size increases with shape fabric from $2,617.8$ pixels per grain for the equiaxed microstructure to 2,881.8 pixels per grain for the mixed microstructure to 3,205.1 pixels per grain for the elongated microstructure.

The coordinate system, shown in Fig. 3, is used to describe the results: the $y$ direction is parallel to the SPO; the $x$ direction is perpendicular to the SPO and in the plane of the microstructure; and the $z$ direction is perpendicular to the SPO and out of the plane of the microstructure.

\section{Crystal texture}

Orientation distribution functions (ODFs) with LPOs were generated via the March Dollase fiber-texture distribution (Dollase 1986; Blendell et al. 2004). Given a texture direction and the crystallographic axes to be textured, in this case the crystallographic $c$-axes, the cumulative fraction of $c$-axis orientations within a cone of half angle $\theta$ about the texture direction is given by:

$P(M, \theta)=1-\cos (\theta) / \sqrt{\cos ^{2}(\theta)+M \sin ^{2}(\theta)}$

where $M$ is a parameter characterizing the degree of texture. The probability distribution function is given by $\partial P(M, \theta) / \partial \theta=f(M, \theta) \sin (\theta)$, where

$f(M, \theta)=M /\left[\cos ^{2}(\theta)+M \sin ^{2}(\theta)\right]^{3 / 2}$

gives the multiple of a random distribution (MRD) at that value of $\theta$.

If $M=1, f(M=1, \theta)=1$, and the distribution is random. If $M>1$, one has fiber texture in a cone of half angle $\theta$ (the $c$-axis fiber types considered here). The maximum 

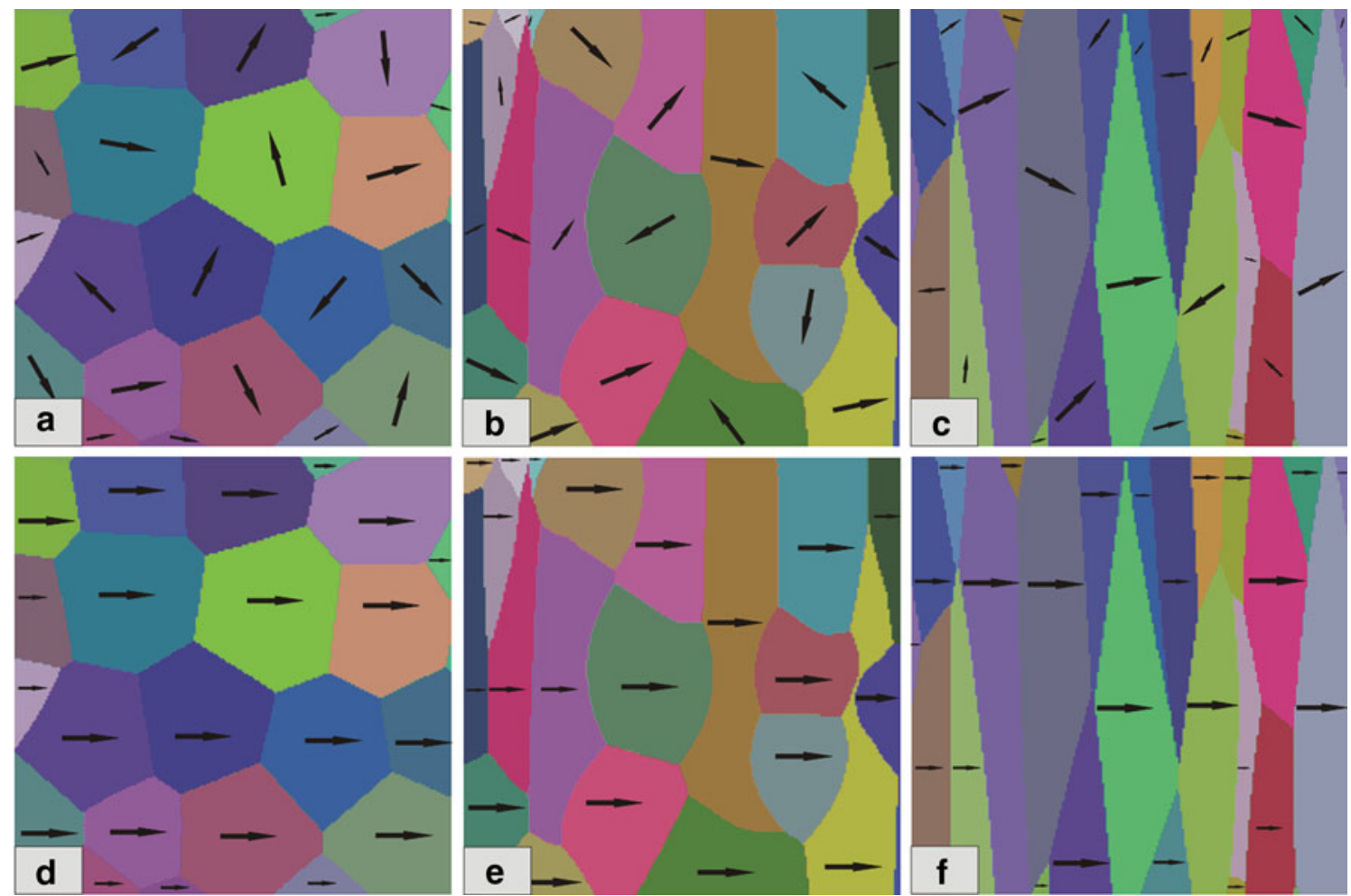

Fig. 2 A schematic illustration of the extremes of shape fabric and crystalline texture. From left to right are shown two extremes of shape fabric and a mixture of the extremes: $\mathbf{a}, \mathbf{d}$ an equiaxed microstructure; $\mathbf{c}, \mathbf{f}$ an elongated grain shape; $\mathbf{b}, \mathbf{e}$ a mixed microstructure with shape fabric from the two extremes. From top to bottom are shown two

extremes of crystallographic texture: a-c random crystallographic texture; and $\mathbf{d}-\mathbf{f}$ extreme crystallographic texture. Also examined, but not shown is the directionality of the crystallographic texture with respect to the shape fabric, i.e., either parallel or perpendicular to the shape fabric
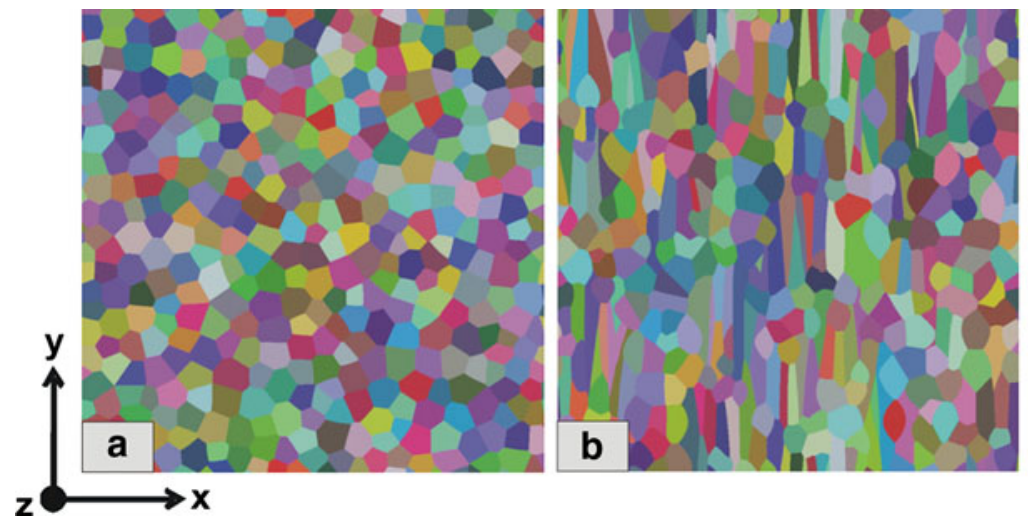

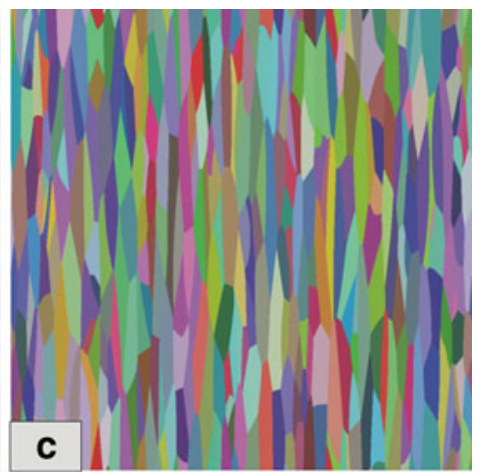

respectively, are 382 grains, 347 grains, and 312 grains. The coordinate systems used to describe the results is also indicated in the figure

Tric: a an equiaxed microstr with shape fabric from the two extremes; and $\mathbf{c}$ an elongated grain shape microstructure. The number of grains in each microstructure,

MRD occurs at $\theta=0$, and is equal to $M$. Perfect fiber texture is defined as texture with axial symmetry. It can be envisioned as a single crystal rotating around a specific axis. In the case of $c$-axis perfect fiber texture, the rotation axis is the $c$-axis. There is a single $c$-axis maximum, the $a$-axes are distributed on a great circle, and the normals of other crystallographic planes are distributed on small circles. If $M<1$, a case not considered here, one has girdle texture outside a cone of half angle $\theta$. The maximum MRD occurs at $\theta=\pi / 2$, and is equal to $1 / \sqrt{ } M$. Such distributions with $M<1$ could be used to describe the $a$-axis fiber types.

Three ODFs (or three LPOs) were considered: a random ODF (i.e., $M=1$ ); an ODF with fiber-texture that is 20 times random (i.e., $M=20$ ); and an ODF with fiber- 
texture that is 40 times random (i.e., $M=40$ ). For brevity in labeling the simulation results, the three LPOs are denoted as $M 1, M 20$, and $M 40$, respectively. For all cases the half-angle $\theta$ of the cone containing the crystal $c$-axis was selected from the March-Dollase distribution described by Eq. (1). Using a random number between 0 and 1 for the cumulative probability $P$, the polar angle of the orientation is given by:

$\theta=\arccos \left(\sqrt{\frac{M(1-P)^{2}}{1+(M-1)(1-P)^{2}}}\right)$

The two Azimuthal angles describing the crystal orientation, $\varphi$ and $\omega$, were selected randomly from the interval 0 to $2 \pi$.

Representative pole figures for the three ODFs considered here are shown in Fig. 4. These pole figures are for one of the five replications generated for the equiaxed microstructure, but are typical of all 105 pole figures. The fiber texture is along the North-South direction in these figures, but variants are considered where texture direction is rotated with respect to the SPO. The pole figures show the individual poles of the crystallographic $c$-axis for each grain in the microstructure. The contour lines are selected MRD contours from the March-Dollase distribution, from which the orientations were chosen. The distributions become more textured as the maximum MRD in the March-Dollase function (i.e., $M$ ) varies from 1 (untextured) to 40 (highly textured).

\section{Crystal texture direction}

Both the LPO and the SPO have directionality. For textured microstructures there are three possible relations between them. Since here the SPO is always aligned along the $y$-axis, these three relations are specified by the orientation of the LPO. The designations $x, y$, and $z$, are used to correspond to the $c$-axes having fiber texture along $x$-axis (in plane and perpendicular to the shape fabric), $y$-axis (parallel to the shape fabric), and $z$-axis (out of plane and perpendicular to the shape fabric), respectively.

\section{Microstructure-based finite-element approach}

The microstructure-based finite-element approach used here is based on the Object-Oriented Finite Element program (OOF) developed at the National Institute of Standards and Technology (Langer et al. 2001). The $O O F$ software is in the public domain. Executables, source code, and manuals are available at: http://www.nist.gov/msel/ ctcms/oof/. The OOF1 software was used here.

The finite-element meshing procedure is described in detail elsewhere (Langer et al. 2001; Weiss et al. 2002; Chawla et al. 2003; Saylor et al. 2007; Wanner et al. 2010). Briefly, a uniform $200 \times 200$ mesh of 80,000 right triangular elements was positioned on the $1,000 \times 1,000$ pixel microstructure. Then an adaptive meshing algorithm was used to align the nodes of inhomogeneous elements (i.e., those which overlapped two or more grains) with the grain boundaries. The resulting finite-element meshes consisted of 80,000 triangular elements, which have an average area of $12.50 \pm 3.80$ pixels per element for the equiaxed microstructure, $12.50 \pm 3.74$ pixels per element for the mixed microstructure, and $12.50 \pm 3.66$ pixels per element for the elongated microstructure. The element size distribution was kept relatively uniform so that microstructural statistics over the microstructure are more meaningful.

After the finite-element mesh was generated, thermophysical properties of calcite (trigonal symmetry) were assigned to the elements. The single-crystal values for the coefficients of thermal expansion (Kleber 1959) and the

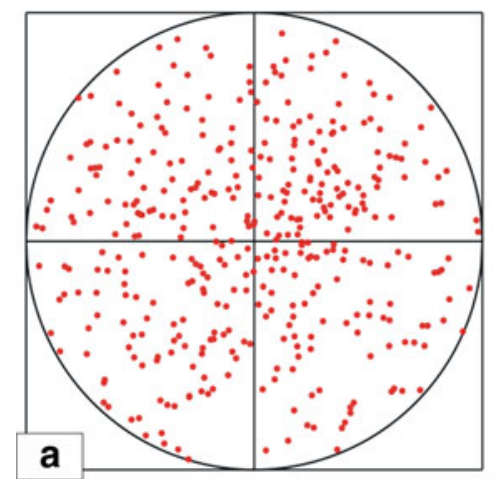

Fig. 4 Representative pole figures showing the individual poles of the crystallographic c-axis for each grain in the microstructure. In a the orientations were chosen from a random ODF. In $\mathbf{b}$ the orientations were chosen from a March-Dollase ODF with fiber texture along the North and South pole that is 20 times random. In
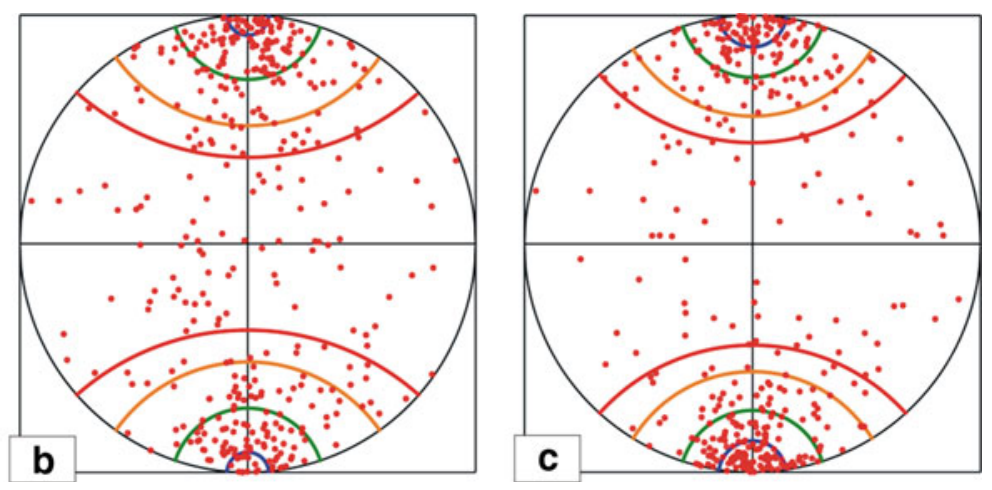

c the orientations were chosen from a March-Dollase ODF with fiber texture along the North and South pole that is 40 times random. For both $\mathbf{b}$ and $\mathbf{c}$ the contour lines correspond to multiple random distribution (MRD) from the March-Dollase distribution function of 16 (blue), 4 (green), 1 (orange) and 1/2 (red) 
Table 1 The single-crystal coefficient of thermal expansion for calcite in units of ${ }^{\circ} \mathrm{C}^{-1}$ (Kleber 1959)

\begin{tabular}{ll}
\hline$\alpha_{11}=\alpha_{22}$ & $\alpha_{33}$ \\
\hline$-6.0 \times 10^{-6}$ & $26.0 \times 10^{-6}$ \\
\hline
\end{tabular}

Table 2 The single-crystal elastic stiffness coefficients for calcite in units of GPa (Bass 1995)

\begin{tabular}{llllll}
\hline $\mathrm{C}_{11}$ & $\mathrm{C}_{12}$ & $\mathrm{C}_{13}$ & $\mathrm{C}_{14}$ & $\mathrm{C}_{33}$ & $\mathrm{C}_{44}$ \\
\hline 144.0 & 53.9 & 51.1 & -20.5 & 84.0 & 33.5 \\
\hline
\end{tabular}

elastic stiffness coefficients (Bass 1995) are given in Tables 1 and 2, respectively. The crystallographic orientations of each grain were selected from the appropriate ODF, as described above, and were from three-dimensional distributions.

Upon heating or cooling from a stress-free state, the misorientation between neighboring grains and the associated thermal expansion anisotropy result in thermal misfit strains. These strains in turn give rise to internal residual stresses, which are computed by the finite element method. The temperature change used here was a temperature increase of $+100^{\circ} \mathrm{C}$ (i.e., heating). All of the finite-element simulations used two-dimensional elasticity with a planestress assumption, thereby simulating a free surface.

Effective polycrystalline in-plane coefficients of thermal expansion coefficient were computed by measuring the relative dimensional changes of the simulation microstructure and dividing by the temperature change. These effective values represent only the contribution to the thermal expansion (or contraction) from the elastic thermal misfit strains. If microcracking occurs, for example in a real microstructure, or if it is included in the simulations, an additional expansion will occur, which is independent of whether the temperature change is heating or cooling. The total thermal expansion (or contraction) is the sum of the elastic thermal expansion (contraction) and the microcracking expansion.

\section{Results and discussion}

Shape preferred orientation (SPO) and lattice preferred orientation (LPO)

Myriad SPO and LPO are observed for calcite in limestone and marble. Calcite is easily deformable at low temperatures, as is known from natural examples and from laboratory deformation studies (e.g., Leiss and Molli 2003). SPO is common in calcite and mainly results via plastic deformation. Nonetheless, recrystallization and grain- coarsening can reset the grain shapes to an equiaxed fabric (Shelley 1993).

As is the case for most rock-forming minerals, LPO for calcite strongly depends on the active slip systems, and on the geometry and symmetry of the flow pattern. This results in a LPO geometry that is similar to the strain geometry (Wenk et al. 1987; Kern and Wenk 1983; Shelley 1993; Passchier and Throuw 1996). For example, in uniaxial compression, calcite develops a LPO with the $c$-axes close to the shortening direction and at a high angle to foliation, i.e., $c$-axes have a maximum around the compression axis. In constriction a $c$-axes-girdle develops perpendicular to an $a$-axis. Geometrically, the fundamental LPO-types for calcite (i.e., perfect texture) can be simply described by a rotating single crystal about the $c$-axis or about one of the $a$-axes ( $c$ - and $a$-axis fibertype), or by any continuous sequence between these two idealized end-members, e.g., Leiss and Ullemeyer (1999) or Weiss et al. (1999).

\section{Elastic strain energy density}

The elastic strain energy density, $U$, is a key indicator of potential microcracking sites in a microstructure, as it provides the surface energy necessary to create the fracture surfaces of the microstructural cracks. Accordingly, to elucidate factors related to marble degradation from microcracking phenomena, the influences of shape fabric and crystallographic texture on the elastic strain energy density were studied by microstructural simulations. Variables observed were (1) the average elastic strain energy density for the microstructure and (2) the variation of the strain energy density throughout the microstructure, as characterized by the standard deviation of the strain energy density distribution.

\section{Elastic strain energy density: influence of SPO}

The influence of shape fabric on the elastic strain energy density, as characterized by the three SPO types (equiaxed, mixed, and elongated), is minimal when the crystallographic texture is random (i.e., $M=1$, or no LPO). See $M 1$ in Fig. 5. The average strain energy density shows a small decrease from $31.5 \pm 0.7 \mathrm{~kJ} \mathrm{~m}^{-3}$ for the equiaxed microstructure to $29.8 \pm 2.1 \mathrm{~kJ} \mathrm{~m}^{-3}$ for the mixed microstructure and to $28.3 \pm 1.5 \mathrm{~kJ} \mathrm{~m}^{-3}$ for the elongated microstructure. The variation represents the standard deviation over the five simulation replications using five different random ODFs.

The variation of the strain energy density within the microstructure, microstructural standard deviation, similarly shows little dependence on shape fabric for random crystallographic texture. The microstructural standard 
Fig. 5 Elastic strain energy density and its microstructural standard deviation (the square root of its variance throughout the microstructure) as a function of SPO and LPO for a temperature change of $+100^{\circ} \mathrm{C}$. The different LPOs, or crystal texture ODFs, are denoted as $M 1, M 20$ and $M 40$, respectively corresponding to a MarchDollase parameter $M$ of 1,20 , and 40 for the distribution from which the orientations were chosen. The errors bars show the standard deviation from five independent replications of the ODF. Three directions for the LPOs were observed: $x, y$ and $z$, corresponding to the $c$-axes having fiber texture along $x$-, $y$-, and $z$-axis, respectively
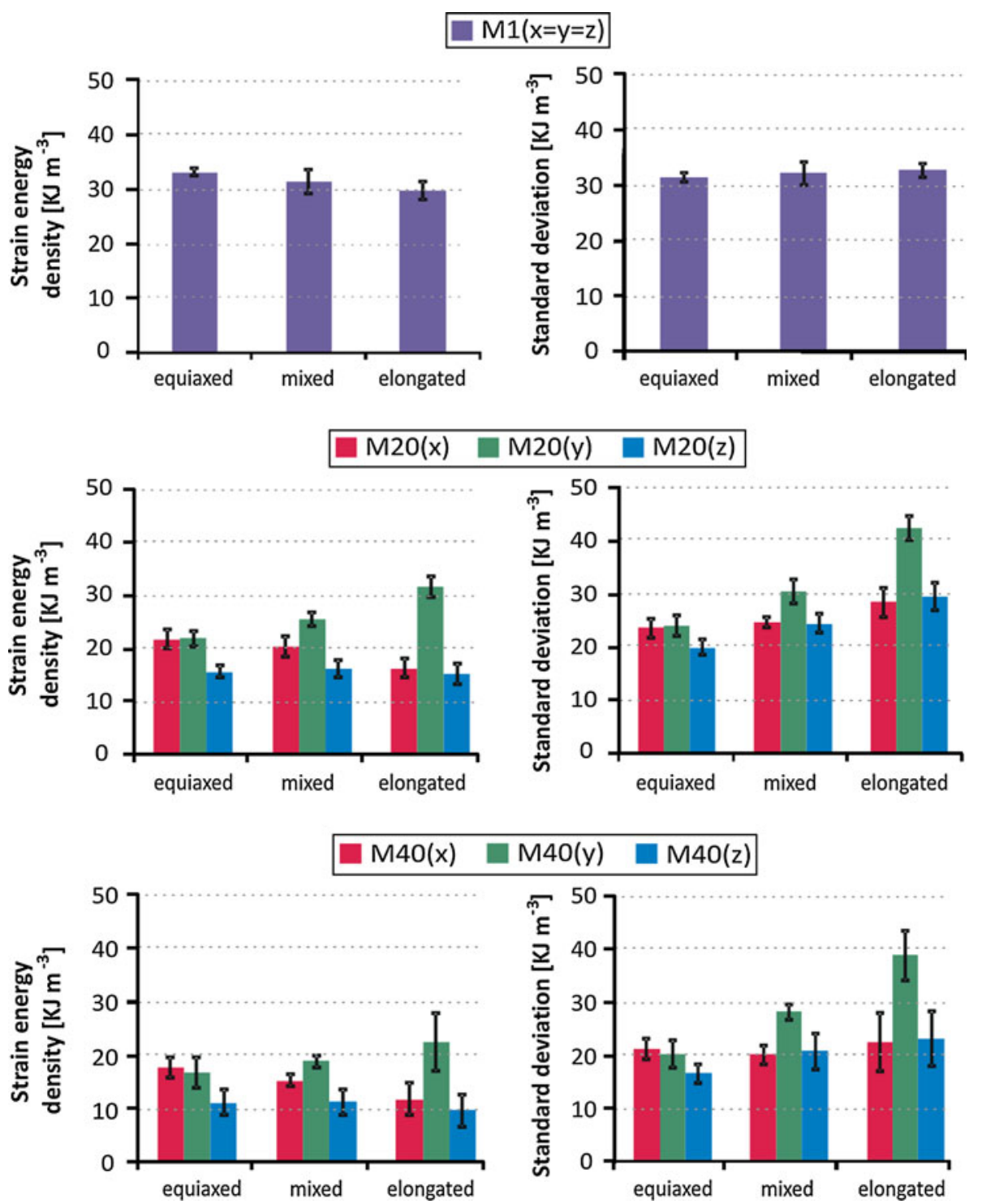

deviation of the strain energy density distribution increases from $29.7 \pm 0.8 \mathrm{~kJ} \mathrm{~m}^{-3}$ for the equiaxed microstructure to $30.3 \pm 2.0 \mathrm{~kJ} \mathrm{~m}^{-3}$ for the mixed microstructure and to $30.8 \pm 1.1 \mathrm{~kJ} \mathrm{~m}^{-3}$ for the elongated microstructure. Again, the variation is the standard deviation from the five simulation replications of the random ODF.

Note that the variation of the strain energy density within the microstructure is as large as the average strain energy density. The frequency distributions of strain energy density throughout the microstructure is essentially a decreasing function with the largest fraction of strain energy densities in the microstructure, as discretized by the finite elements, lying at low values. The upper tail of the frequency distribution of strain energy density is expected to be characteristic of the propensity for microcracking. However, a measure of this upper tail, i.e., the strain energy density at $90 \%$ cumulative probability, essentially mimics the average strain energy density, so it is not reported here separately.

When the LPO has fiber texture that has a maximum value of 20 times random, i.e., $M=20$, the strain energy density shows a significant dependence on the shape fabric. Moreover, this dependence is strongly influenced by the direction of the LPO with respect to the SPO. See M20 in Fig. 5. For the equiaxed microstructure there is no SPO. Thus, the strain energy density values should statistically be the same whether the crystal texture is along the $x$ - or the $y$-directions. This is observed to be the case. However, for the mixed and the elongated microstructures the strain energy density value is significantly larger when the $c$-axis crystal texture is aligned with the SPO, i.e., the $y$ direction. In contrast, when the $c$-axis crystal texture is perpendicular to the SPO, i.e., the $x$ direction, the strain energy density value decreases with shape fabric. When the $c$-axis crystal 
texture is out of the plane of the simulation, i.e., the $z$ direction, the strain energy density values are smaller and exhibit only a minor dependence.

However, the variation of the strain energy density, as characterized by the microstructural standard deviation, increases with increasing shape fabric for all three directions of the LPO $(x, y$ and $z)$ and is the largest for the elongated microstructure. Furthermore, the microstructural variation is substantially larger than the average value, and the standard deviation of these standard deviation values increases with increasing fabric shape. See Fig. 5.

When the LPO has fiber texture that has a maximum value of 40 times random, i.e., $M=40$, the strain energy density exhibits a similar dependence with shape fabric and LPO to that of $M 20$, but slightly smaller. See M40 in Fig. 5. However, the standard deviation of these standard deviation values is larger than that of $M 20$, i.e., there is more variation in the five replications of the ODF.

\section{Elastic strain energy density: influence of LPO}

With one exception, as the crystal texture increases from untextured or random $(M=1)$ to a high degree of fiber texture $(M=40)$, the average strain energy density and its microstructural variation (the microstructural standard deviation) decrease. Thus, in most cases increased LPO or crystal texture reduces the propensity for microstructural microcracking.

The one exception is for an elongated microstructure when the crystallographic $c$-axis texture is aligned parallel with the SPO direction (i.e., the crystalline $c$-axes are aligned along the shape fabric $y$ direction). For this combination of LPO and SPO, the average strain energy density first increases with crystal texture from $28.3 \pm 1.5 \mathrm{~kJ} \mathrm{~m}^{-3}$ for $M=1$ to $30.8 \pm 1.8 \mathrm{~kJ} \mathrm{~m}^{-3}$ for $M=20$ and then decrease with further crystal texture to $21.7 \pm 5.3 \mathrm{~kJ} \mathrm{~m}^{-3}$ for $M=40$. Similarly, the microstructural standard deviation of the strain energy density distribution increases with crystal texture from $30.8 \pm 1.1 \mathrm{~kJ} \mathrm{~m}^{-3}$ for $M=1$ to $41.4 \pm 2.1 \mathrm{~kJ} \mathrm{~m}^{-3}$ for $M=20$ and then decrease to $37.4 \pm 4.5 \mathrm{~kJ} \mathrm{~m}^{-3}$ for $M=40$. The reason for this phenomenon is that several elongated grains per chance are crystallographically misoriented with respect to the average LPO. Initially, the elastic strain energy from these misaligned grains dominate the strain energy density distribution, giving rise both to more microstructural variation and to a slight increase in the average value. With increasing crystalline texture alignment, the effect diminishes. However, the phenomenon, which is described further in the section on microstructural stress maps, is probably unrealistic for two reasons. First, the crystal texture is probably correlated with the shape texture, so these misoriented grains are not highly probable. Second, typical LPOs for calcite marbles are such that the $c$-axes are aligned perpendicular to the SPO, i.e., the crystalline $c$-axes are aligned along the shape fabric $x$ or $z$ directions (e.g., Leiss and Ullemeyer 1999).

\section{Maximum principal stress: influence of SPO}

The dependence of the maximum principal stress and its microstructural standard deviation on the SPO and the LPO is essentially the same as that for the elastic strain energy density. Figure 6 shows the average maximum principal stress and the microstructural standard deviation for the microstructure configurations investigated in this study. The error bars represent the standard deviation for the five replications of the ODF.

For the random ODFs ( $M 1$ in Fig. 6) there is slight, but insignificant decrease in the maximum principal stress with shape fabric: $34.7 \pm 0.4 \mathrm{MPa}$ for the equiaxed fabric; $33.1 \pm 1.1 \mathrm{MPa}$ for the mixed fabric; and $30.5 \pm 0.9 \mathrm{MPa}$ for the elongated fabric. For the textured ODFs (M20 and M40 in Fig. 6) the values for the $x$ and $y$ directions are statistically equivalent for the equiaxed fabric, and respectively, show decreases and increases with shape fabric that are similar to those for the strain energy density. The most significant variation with shape fabric is seen for the M20 microstructural standard deviation when the crystal texture is parallel to the shape texture (the $y$ direction): $29.9 \pm 1.5 \mathrm{MPa}$ for the equiaxed fabric; $35.4 \pm 2.1 \mathrm{MPa}$ for the mixed fabric; and 47.2 $\pm 1.6 \mathrm{MPa}$ for the elongated fabric. As in the discussion for the strain energy density, this phenomenon may be unrealistic. For the highly textured ODFs (M40) all values are decreased from the $M 20$ values.

\section{Maximum principal stress: microstructural maps}

Spatial variations of the maximum principal stress are shown in Fig. 7 for the three shape fabrics, the three degree of crystallographic texture, and the three directions of LPO with respect to SPO. The stress values are shown with a thermal scale that ranges from black (0 MPa) to red-orange (125 MPa) to white ( $\geq 250 \mathrm{MPa})$. Each of the 27 microstructural maps shows the results for one of the five replications of the ODFs for that configuration. However, as the results for the $M=1$ rows are for a random ODF, the maps in Fig. 7a, b, c for each shape fabric of this row are statistically equivalent. Similarly, but now due to the equiaxed fabric, the maps in Fig. $7 \mathrm{a}, \mathrm{b}$ for the equiaxed fabric column are statistically equivalent. Comparing these equivalent maps, one can see the variations that arise from the different ODFs and from the different equiaxed fabric directions. These variations are reflected quantitatively by the standard deviations of the maximum principal stress 
Fig. 6 Maximum principal stress and its microstructural standard deviation (the square root of its variance throughout the microstructure) as functions of SPO and LPO for a

temperature change of $+100^{\circ} \mathrm{C}$. The different LPOs, or crystal texture ODFs, are denoted as $M 1, M 20$ and $M 40$, respectively corresponding to a March-

Dollase parameter $M$ of 1,20 , and 40 for the distribution from which the orientations were chosen. The errors bars show the standard deviation from five independent replications of the ODF. Three directions for the LPOs were observed: $x, y$ and $z$, corresponding to the $c$-axes having fiber texture along $x$-, $y$-, and $z$-axis, respectively
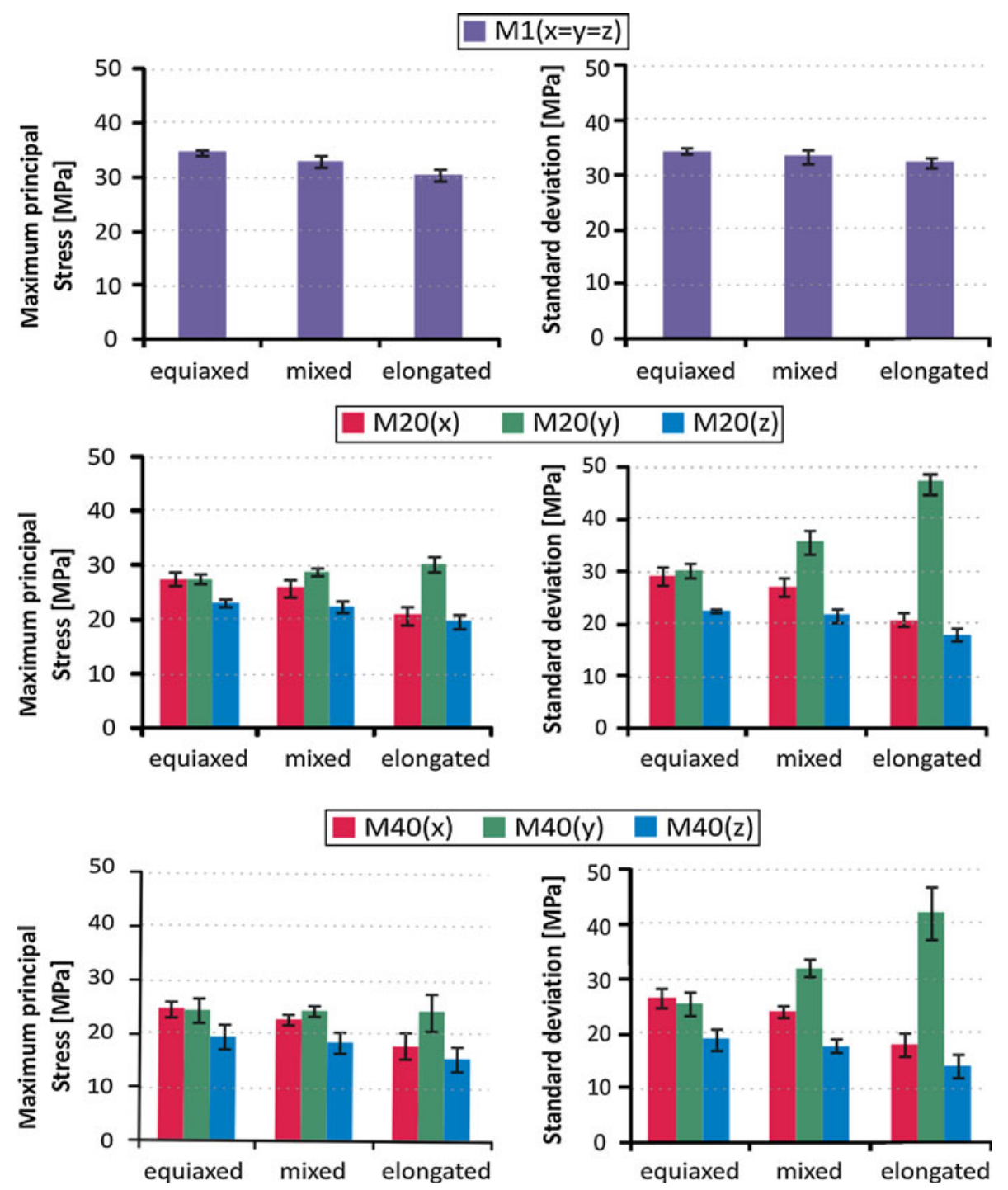

values (the error bars in Fig. 6). Similar variations occur for the other replications of the ODFs for $M=20$ and $M=40$ that are not reflected in Fig. 7. The statistical variation between replications of the ODFs is not to be confused with the microstructural standard deviation, shown in Fig. 6 (and in Fig. 5 for the strain energy density). The microstructural standard deviation represents the standard deviation of the maximum principal stress values (or strain energy density values) within a single microstructural configuration.

For random crystal texture $(M=1)$ the overall range of the maximum principal stress values does not change significantly with SPO. However, the patterns in the stress maps reflect the shape fabric. For the equiaxed fabric, and to some extent for the mixed fabric, the stress patterns show the network structure described by Wanner et al. (2010). This structure of a high-stress network surrounding low-stress regions (the darker regions in Fig. 7) develops due to neighborhoods of grains having similar crystallographic orientations, thereby locally minimizing the thermal expansion anisotropy misfit strains. This network structure persists for microstructure with increasing inplane LPO (i.e., for $M=20$ and $M=40$, when the crystal texture is along the $x$ or the $y$ direction, i.e., in-plane).

For increasing in-plane crystal texture $(M=20$ and $M=40$ ) and SPO, the regions with relatively high maximum principal stress decrease when the crystal texture is perpendicular to the SPO, i.e., in the $x$ direction (see Fig. 7a). This is the typical LPO for calcite marbles (e.g., Leiss and Ullemeyer 1999). Hence, the propensity for microcracking should decrease for calcite marbles with increasing LPO and SPO.

In contrast, when the crystal texture is parallel to the SPO, i.e., in the $y$ direction, the regions with relatively high maximum principal stress increase noticeably for increasing LPO and SPO (see Fig. 7b). This observation is 

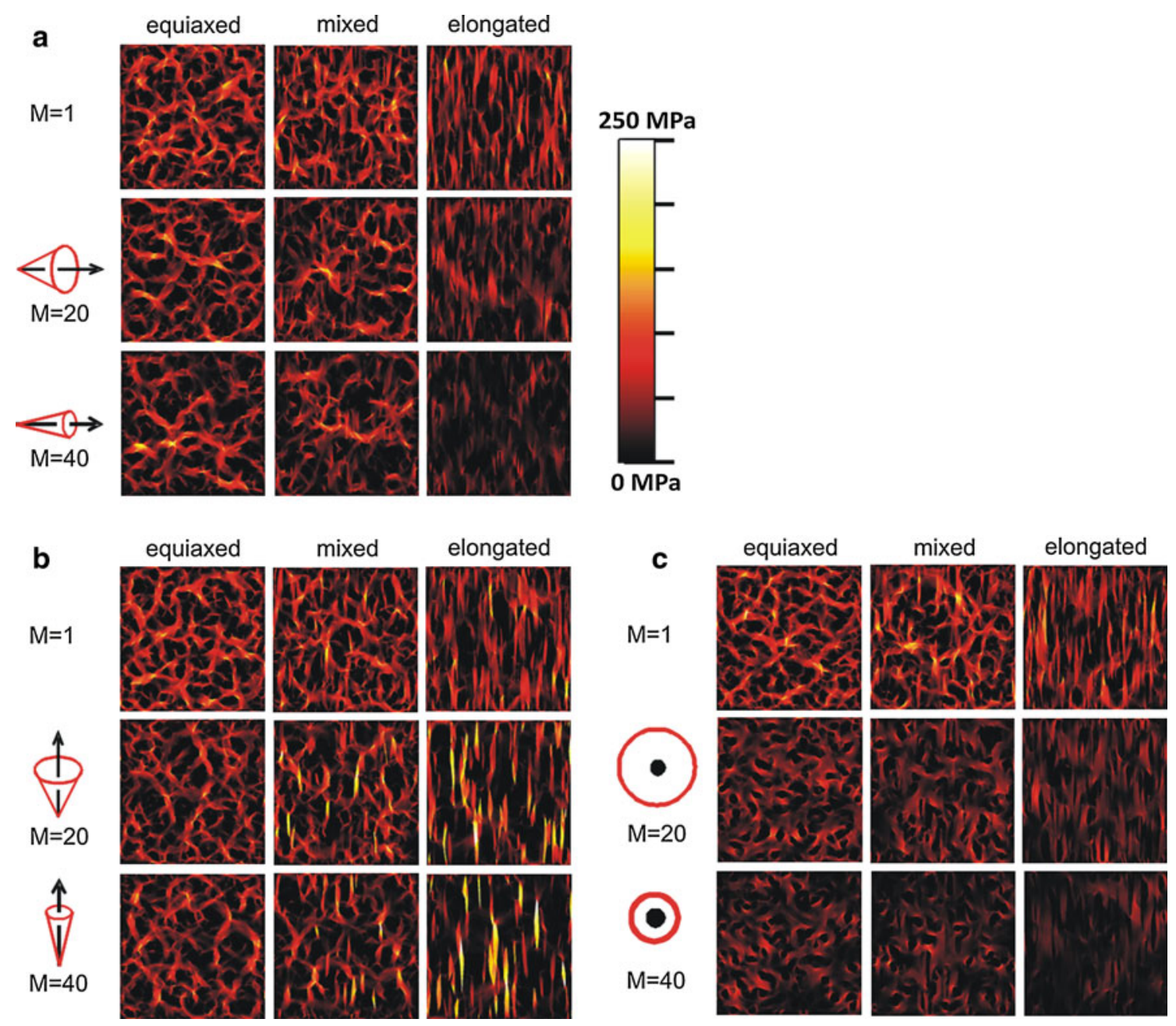

Fig. 7 Microstructural maps showing the spatial dependence of the maximum principal stress for the three shape fabrics and the three degree of crystallographic texture: a the crystal texture is perpendicular to the shape fabric direction and in the plane of the microstructure ( $c$-axes are textured along the $x$-direction); $\mathbf{b}$ the crystal texture is parallel to the shape fabric direction (the $c$-axes are textured along the

$y$-direction); and $\mathbf{c}$ the crystal texture is perpendicular to the shape fabric direction and out of the plane of the microstructure (the $c$-axes are textured along the $z$-direction). Stresses are shown with a thermal scale that ranges from black (0 MPa) to red-orange (125 MPa) to white $(\geq 250 \mathrm{MPa})$

apparently counter to the results in Fig. 6, where the average value of maximum principal stress for the elongated fabric initially remains constant and then decreases as $M$ increases from 1 to 20 to 40 . The explanation is in the microstructural standard deviation of the maximum principal stress, which increases as $M$ increases from 1 to 20 , and only slightly decreases as $M$ increases further from 20 to 40 . This observation is related to the same phenomenon described above for the strain energy density. By random chance several of the elongated grains are crystallographically misoriented with respect to the general LPO. Namely, these grains have large values of the fiber texture angle $\theta$, which is not in concord with the expected probability distribution. Accordingly, the long direction of these grains has a low coefficient of thermal expansion (a value somewhat greater than that of the basal plane, i.e.,

$-6.0 \times 10^{-6 \circ} \mathrm{C}^{-1}$ ), while the textured matrix, in which they lay, has an average coefficient of thermal expansion in that direction that is somewhat less than that of the $c$-axis, i.e., $26.0 \times 10^{-6 \circ} \mathrm{C}^{-1}$. Thus, on heating the long direction of these misoriented grain contracts, or only slightly expands, in a direction where the remainder of the microstructure is greatly expanding. Hence, these misoriented elongated grains have large axial tension. Therefore, even though the average value of maximum principal stress for the elongated fabric initially remains constant with crystal texture and then decreases, these microstructures could have a greater propensity for microcracking, since fracture is determined by the extremes in the distribution, not by the mean.

The stress state of these grains is better seen in Fig. 8, where the stress components in the $x$ and $y$ directions, $\sigma_{x x}$ 
Fig. 8 Microstructural maps of the stress tensor components $\sigma_{x x}$ and $\sigma_{y y}$ and the maximum principal stress for the elongated shape fabric, which has large $(M=40)$ in-plane crystal texture, a perpendicular to the shape fabric (along the $x$ directions) and $\mathbf{b}$ parallel to the shape fabric (along the $y$ direction). The stress tensor components are shown with a thermal scale that ranges from black ( $\leq-250 \mathrm{MPa})$ to redorange ( $0 \mathrm{MPa})$ to white $(\geq+250 \mathrm{MPa})$. The thermal scale for the maximum principal stress is the same as that for Fig. 7
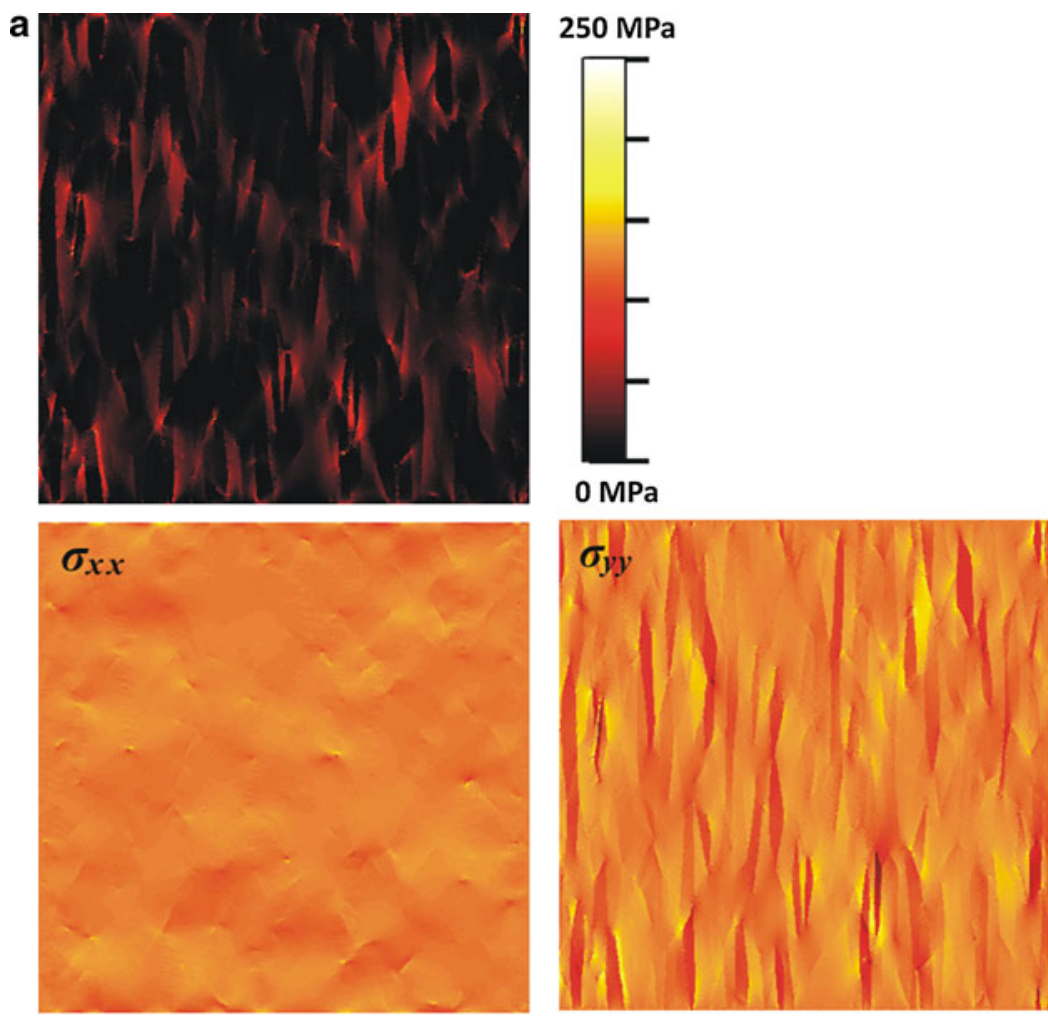

$250 \mathrm{MPa}$

b

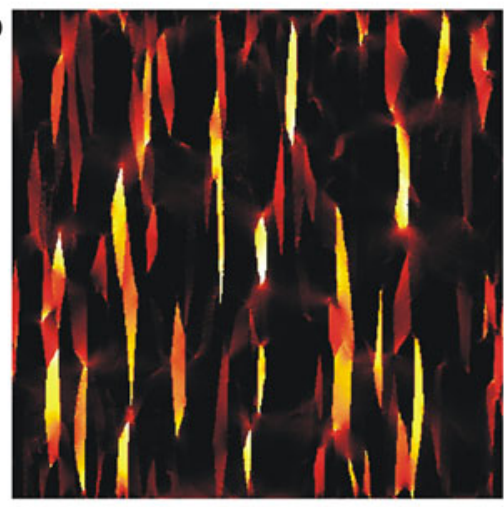

$250 \mathrm{MPa}$
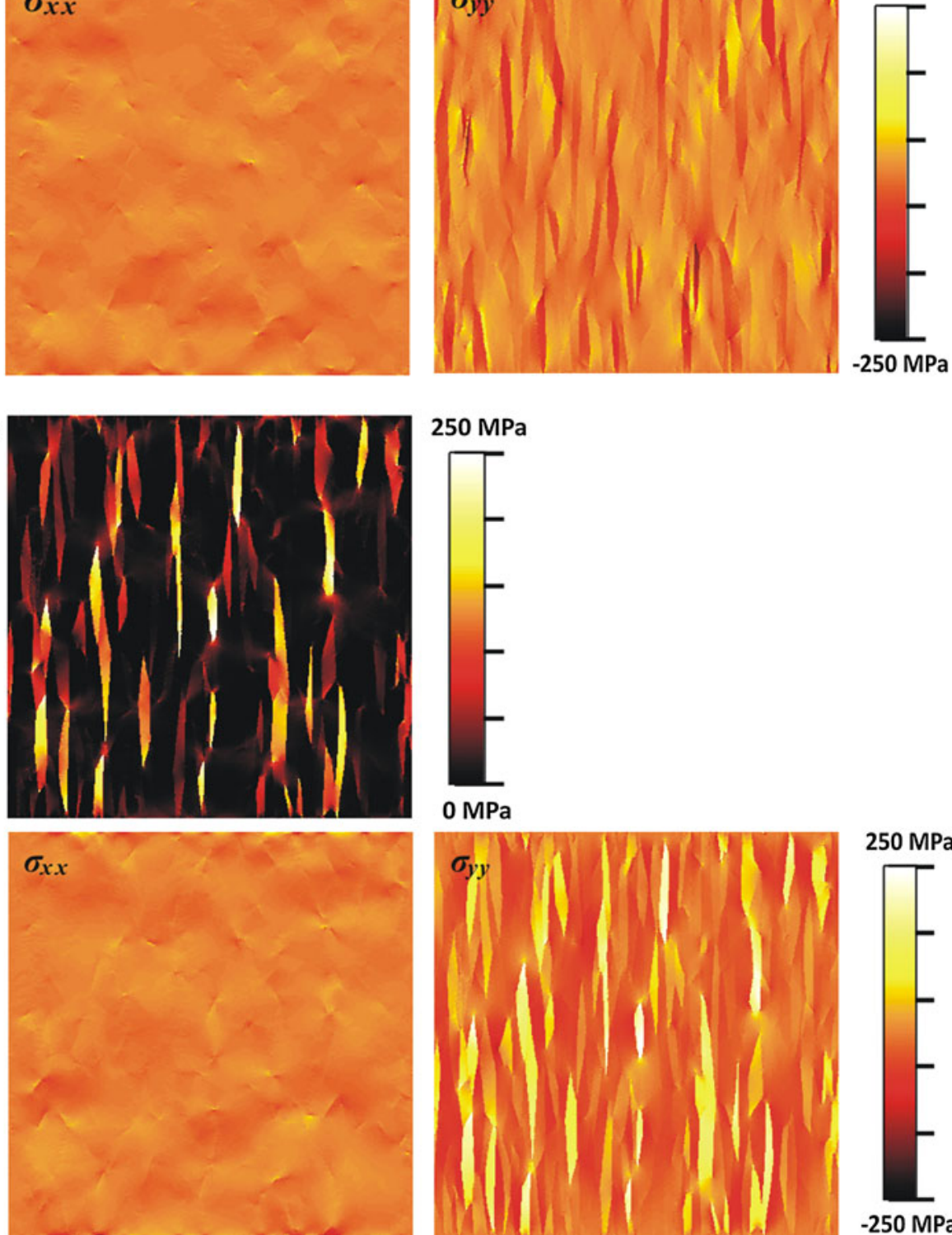

$250 \mathrm{MPa}$

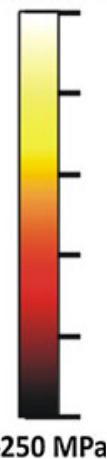

and $\sigma_{y y}$, respectively, are shown along with the maximum principal stress. The thermal scale for the stress components $\sigma_{x x}$ and $\sigma_{y y}$ ranges from black $(\leq-250 \mathrm{MPa})$ to redorange $(0 \mathrm{MPa})$ to white $(\geq+250 \mathrm{MPa})$. The thermal scale for the maximum principal stress is the same as that for Fig. 7. From Fig. 8a, when the crystalline $c$-axis is textured perpendicular to the SPO direction, grains with a relatively high value of the maximum principal stress, the yellow- 
Table 3 The effective coefficients of thermal expansion in the $x$ - and $y$-directions, $\alpha_{x}^{\text {eff }}$ and $\alpha_{y}^{\text {eff }}$, in units of $10^{-6}{ }^{\circ} \mathrm{C}^{-1}$ for the three shape fabrics (equiaxed, mixed, and elongated), the three degrees of LPO
(M1, M20, and M40), and the three directions of crystallographic texture with respect to SPO (denoted by $c-x, c-y$, and $c-z$ for when the $c$-axes are aligned along $x$-, $y$ - and $z$-direction, respectively)

\begin{tabular}{|c|c|c|c|c|c|c|c|c|c|}
\hline & \multicolumn{3}{|l|}{ Equiaxed } & \multicolumn{3}{|l|}{ Mixed } & \multicolumn{3}{|l|}{ Elongated } \\
\hline & $c-x$ & $c-y$ & $c-z$ & $c-x$ & $c-y$ & $c-z$ & $c-x$ & $c-y$ & $c-z$ \\
\hline \multicolumn{10}{|l|}{$M 1$} \\
\hline$\alpha_{x}^{\mathrm{eff}}$ & $4.1 \pm 0.6$ & $4.1 \pm 0.6$ & $4.1 \pm 0.6$ & $4.0 \pm 0.5$ & $4.0 \pm 0.5$ & $4.0 \pm 0.5$ & $4.1 \pm 0.8$ & $4.1 \pm 0.8$ & $4.1 \pm 0.8$ \\
\hline$\alpha_{y}^{\mathrm{eff}}$ & $4.1 \pm 0.6$ & $4.1 \pm 0.6$ & $4.1 \pm 0.6$ & $4.0 \pm 0.5$ & $4.0 \pm 0.5$ & $4.0 \pm 0.5$ & $4.1 \pm 0.8$ & $4.1 \pm 0.8$ & $4.1 \pm 0.8$ \\
\hline \multicolumn{10}{|l|}{$M 20$} \\
\hline$\alpha_{x}^{e f f}$ & $17.0 \pm 0.5$ & $-2.2 \pm 0.1$ & $-1.9 \pm 0.4$ & $17.0 \pm 0.8$ & $-1.9 \pm 0.3$ & $-1.6 \pm 0.5$ & $17.5 \pm 0.8$ & $-1.8 \pm 0.6$ & $-1.8 \pm 0.6$ \\
\hline$\alpha_{y}^{\text {eff }}$ & $-2.0 \pm 0.4$ & $17.0 \pm 0.5$ & $-2.2 \pm 0.2$ & $-1.9 \pm 0.5$ & $16.5 \pm 0.8$ & $-2.2 \pm 0.6$ & $-2.3 \pm 0.5$ & $16.4 \pm 1.0$ & $-2.2 \pm 0.5$ \\
\hline \multicolumn{10}{|l|}{$M 40$} \\
\hline$\alpha_{x}^{\text {eff }}$ & $19.2 \pm 1.0$ & $-3.1 \pm 0.5$ & $-3.0 \pm 0.4$ & $19.6 \pm 0.5$ & $-3.1 \pm 0.4$ & $-3.0 \pm 0.2$ & $20.0 \pm 1.1$ & $-3.2 \pm 0.5$ & $-2.9 \pm 0.7$ \\
\hline$\alpha_{y}^{\text {eff }}$ & $-3.1 \pm 0.4$ & $19.2 \pm 1.0$ & $-3.0 \pm 0.5$ & $-3.2 \pm 0.2$ & $19.3 \pm 0.6$ & $-3.2 \pm 0.4$ & $-3.3 \pm 0.6$ & $19.2 \pm 1.3$ & $-3.6 \pm 0.4$ \\
\hline
\end{tabular}

colored grains, are aligned along the crystal texture direction better than the average value. Thus, upon heating they contract more (or expand less) than the average. Hence, these well-aligned elongated grains have moderate axial tension. On the other hand, highly misaligned grains, the red- and black-colored grains, have large axial compression. For plane-stress simulations, the maximum principal stress for a region with in-plane biaxial compression is the zero out-of-plane stress, $\sigma_{z z}$. Thus, the highly misaligned grains are not apparent in the maximum principal stress microstructural maps.

From Fig. $8 \mathrm{~b}$, when the crystalline $c$-axis is texture parallel to the SPO direction, the effect of misaligned grains, as described above, is more striking. Clearly, the grains with large values of the maximum principal stress also have large values of $\sigma_{y y}$. The fact these highly stressed grains were actually misoriented was validated for selected grains by noting the misorientation angle $\theta$ of these grains and by computing the direction of the maximum principal stress. So, while the average value of the maximum principal stress decreases with LPO, the few misoriented grains with large axial tension results in a large variance for the maximum principal stress distribution and hence, the large value of the microstructural standard deviation seen in Fig. 6 for $M 20(y)$ and $M 40(y)$.

The different character of the microstructural maps for the maximum principal stress when the crystal texture is out of the plane of the microstructure can be seen in Fig. 7c. These patterns result from the near isotropic inplane properties that result from this type of crystal texture. Nonetheless, the patterns in the stress maps still reflect the shape fabric. Additionally, the magnitude of the maximum principal stress is reduced from that in Fig. $7 \mathrm{a}, \mathrm{b}$.
These observations clearly show that both grain shape fabric and crystal texture have significant impact on the maximum principal stresses that arise in calcite microstructure due to temperature changes, and hence, on the propensity for microcracking.

\section{Coefficient of thermal expansion}

For a given simulation configuration and a given temperature change, the effective coefficient of thermal expansion coefficient in the $x$ direction, $\alpha_{x}^{\text {eff }}$, is computed from the relative displacement change of the right and left sides of the microstructure. Similarly, the effective coefficients of thermal expansion coefficient in the $y$ direction, $\alpha_{y}^{\text {eff }}$, is computed from the relative displacement change of the top and bottom of the microstructure. The results of these measurements for the various combinations of SPO, degrees of LPO, and the directional relationships between them are given in Table 3. The uncertainty estimates represent the standard deviation from the five independent replications of the ODF.

A distribution-averaged coefficient of thermal expansion tensor in the sample reference frame can also be computed from the crystal coefficient of thermal expansion tensor and the March-Dollase probability distribution function. First the crystal coefficient of thermal expansion tensor is rotated to the sample reference frame using the orientational relationship described by the polar angle, $\theta$, and the two Azimuthal angles, $\varphi$ and $\omega$. Then, the rotated tensor is averaged over all polar angles and all Azimuthal angles weighted by the March-Dollase probability distribution function, $f(M, \theta) \sin (\theta)$, where $f(M, \theta)$ is given by Eq. (2). The tensor values, thus computed, both parallel and perpendicular to the texture direction are given by: 


$$
\begin{aligned}
& M=1 \quad \alpha_{\text {parallel }}^{\text {eff }}=\alpha_{\text {perpendicular }}^{\text {eff }}=4.67 \times 10^{-6 \circ} \mathrm{C}^{-1} \\
& M=20 \quad \alpha_{\text {parallel }}^{\text {eff }}=17.29 \times 10^{-6 \circ} \mathrm{C}^{-1} \\
& \alpha_{\text {perpendicular }}^{\text {eff }}=-1.64 \times 10^{-6 \circ} \mathrm{C}^{-1} \\
& M=40 \quad \alpha_{\text {parallel }}^{\text {eff }}=19.40 \times 10^{-6 \circ} \mathrm{C}^{-1} \\
& \alpha_{\text {perpendicular }}^{\text {eff }}=-2.70 \times 10^{-6 \circ} \mathrm{C}^{-1}
\end{aligned}
$$

As more crystal texture develops going from a random ODF $(M=1)$ to a highly textured ODF $(M=40)$, the effective coefficient of thermal expansion tensor approaches the single-crystal tensor. The change of sign in $\alpha_{\text {perpendicular }}^{\text {eff }}$ from an expansion (a positive value) to a contraction (a negative value) occurs at approximately $M=8.30$. Note, however, that the volume coefficient of thermal expansion, given by the trace of the thermal expansion tensor, is independent of crystal texture (i.e., $M)$ and is equal to $14.0 \times 10^{-6 \circ} \mathrm{C}^{-1}$.

The effective coefficients of thermal expansion in Table 3 show a strong dependence on the degree of LPO (i.e., $M$ ) and on the directional relationship between the thermal expansion tensor and the crystal texture direction (i.e., parallel or perpendicular), but only show a minor influence on the shape fabric. The dependence of the simulation results on the degree of LPO agrees well with that computed for the distribution-averaged coefficient of thermal expansion. Several minor deviations are apparent, however, which are not fully understood at present. The lack of dependence on shape fabric was unexpected. One might have expected the shape fabric to have had a significant influence on the effective thermal expansion when combined with crystalline texture. For example, elongated grains aligned in the crystalline texture direction might have had more of an effect that an ensemble of equiaxed grains. Simulation results seem to show that this is not the case. However, as mentioned above, these effective values represent only the contribution to the thermal expansion or contraction from the elastic thermal misfit strains. If microcracking occurs, an additional expansion will occur, which may depend on shape fabric and any synergy between shape fabric and crystal texture.

\section{Summary and conclusions}

The elastic strain energy density and maximum principal stress are important microstructural properties for predicting microcrack formation. Spatial regions, where these two microstructural properties are large are expected to indicate regions in the microstructure with a propensity for microcracking. Microstructure-based finite-element simulations were used to elucidate not only these spatial regions, but also the average values of these thermoelastic responses and their microstructural standard deviations, i.e., the standard deviation of their spatial distributions. This finite element approach is considered an excellent tool for elucidating influences of the rock's fabric and crystal texture on the thermoelastic behavior of marbles.

Significant observations are

- For random crystallographic texture, i.e., no LPO, shape fabric did not have a significant influence on either the average values or the microstructural standard deviation of the thermoelastic responses. While not necessarily surprising, this observation was not expected. There is, however, spatial dependence to the stress networks that form. These networks of high strain energy density and maximum principal stress mimic the SPO, so this spatial dependence may have an influence on microcrack formation.

- With equiaxed shape fabric, increasing degrees of LPO generally lead to a reduction in the microstructural stresses and the stored elastic strain energy. This effect was expected since crystallographic texture reduces the misfit strains from the thermal expansion anisotropy. As expected, there is minor influence of the direction of the crystal texture, since statistically there is no directionality to the grain fabric.

- LPO in combination with a mixed or elongated shape fabric can synergistically lead to significant effects, which have a strong directional dependence.

- When the LPO is aligned parallel with the SPO direction, the thermoelastic responses increase markedly with shape fabric. The responses with crystal texture are more complex, but essentially either remain constant, increase slightly and then decrease, or decrease. More significantly, however, is the increase of the microstructural standard deviations of these responses, indicating wide microstructural variation of these responses. These microstructural variations are clearly apparent in the microstructural response maps.

- When the LPO is aligned perpendicular to the SPO direction, the thermoelastic responses remain constant or decrease with shape fabric and decrease with crystal texture. The microstructural standard deviations of the strain energy density increase with shape fabric and decrease with crystal texture. The microstructural standard deviations of the maximum principal stress decreases with both shape fabric and crystal texture. Generally, microstructures with this combination of shape fabric and crystal texture will have less of a tendency to microcrack, particularly as the crystal texture increases.

- When the LPO is aligned perpendicular to the SPO direction and out of the plane of the simulation, the in- 
plane thermoelastic responses are nearly isotropic, and are reduced in magnitude accordingly.

- Even though microstructures with aligned LPO and SPO features give the largest thermoelastic responses and microstructural variability, this response may not be significant for several reasons. First, if the crystal texture is correlated with the shape texture, these misoriented grains may not be probable. Second, this LPO is less often reported for calcite marbles. And third, this combination of LPO and SPO would lead to transgranular microcracking perpendicular to the elongated direction of the grains, i.e., axial segmentation of these grains. Such microcracking would therefore depend on a low fracture energy cleavage plane, which may not be the case.

Acknowledgments The authors gratefully acknowledge David M. Saylor for generating the artificial microstructures used in this study with the Microstructure Builder program, which he was developing in collaboration with Carnegie Mellon University and Alcoa Technical Center. Thomas Weiss is gratefully acknowledged for helpful discussions. Financial support for E.R. Fuller at Göttingen University was provided by the Deutsche Forschungsgemeinschaft with the grant: SI 438/39-1, and is gratefully acknowledged. Victoria Shushakova gratefully acknowledges a long-term DAAD fellowship grant.

Open Access This article is distributed under the terms of the Creative Commons Attribution Noncommercial License which permits any noncommercial use, distribution, and reproduction in any medium, provided the original author(s) and source are credited.

\section{References}

Atkinson BK (1984) Subcritical crack growth in geological materials. J Geophys Res 89(B6):4077-4114

Bass JD (1995) Elasticity of minerals, glasses, and melts. In: Ahrens TJ (ed) Handbook of physical constants. American Geophysical Union, Washington, DC, pp 45-63

Battaglia S, Franzini M, Mango F (1993) High sensitivity apparatus for measuring linear thermal expansion: preliminary results on the response of marbles. II Nuovo Cimento 16:453-461

Blendell JE, Vaudin MD, Fuller ER (2004) Determination of texture from individual grain orientation measurements. J Am Ceram Soc 82(11):3217-3220

Chawla N, Patel BV, Koopman M, Chawla KK, Saha R, Patterson BR, Fuller ER, Langer SA (2003) Microstructure-based simulation of thermomechanical behavior of composite materials by Object-Oriented Finite element analysis. Mater Charac 49:395-407

Dollase WA (1986) J Appl Crystallogr 19:267-272

Grelk B, Goltermann P, Schouenborg B, Koch A, Alnæs L (2004) The laboratory testing of potential bowing and expansion of marble. In: Přikryl R (ed) Dimension stone 2004. Taylor \& Francis Group, London, pp 253-260

Grimm WD (1999) Beobachtungen und Überlegungen zur Verformung von Marmorobjekten durch Gefügeauflockerung. In: Siegesmund S, Snethlage R, Vollbrecht A, Weiss T (eds)
Marmor-Konservierung. Zeitschrift der Deutschen Geologischen Gesellschaft, vol 150, no 2, pp 195-235

Henry JP, Paquet J, Tancrez JP (1978) Experimental study of crack propagation in calcite rocks. Int J Rock Mech Min Sci Geomech Abstr 14:85-91

Ito O, Fuller ER (1993) Computer modelling of anisotropic grain microstructure in two dimensions. Acta Metall Mater 41(1):191-198

Kern H, Wenk HR (1983) Calcite texture development in experimentally induced ductile shear zones. Contrib Min Pet 83:231-236

Kessler DW (1919) Physical and chemical tests on the commercial marbles of the United States. Technologic Papers Bureau of Standards, No. 123, Government Printing Office, Washington, DC

Kleber W (1959) Einfiihrung in die Kristallographie. VEB Verlag Technik, Berlin

Koch A, Siegesmund S (2002) On site damage analysis of buildings showing bowing of marble slabs: Fabric vs. type and degree of damage. In: Siegesmund S, Weiss T, Vollbrecht A (eds) Natural stone, weathering phenomena, conservation strategies and case studies. Geological Society Special Publication No. 205, The Geological Society of London, London, pp 298-314

Koch A, Siegesmund S (2004) The combined effect of moisture and temperature on the anomalous behaviour of marbles. Environ Geol 46:350-363

Langer SA, Fuller ER, Carter WC (2001) OOF: an image-based finiteelement analysis of material microstructures. Comput Sci Eng 3:15-23. [OOF is freely available at http://www.ctcms. nist.gov/oof/]

Leiss B, Molli G (2003) High-temperature texture in naturally deformed Carrara marble from Alpi Apuane, Italy. J Struct Geol 25:649-658

Leiss B, Ullemeyer K (1999) Texture characterisation of carbonate rocks and some implication for the modeling of physical anisotropies, derived from idealized texture types. Z Deut Geol Ges 150:259-274

Logan JM, Hastedt M, Lehnert D, Denton M (1993) A case study of the properties of marble as building veneer. Int J Rock Mech Min Sci Geomech Abstr 30(7):1531-1537

Miodownik M, Godfrey AW, Holm EA, Hughes DA (1999) On boundary misorientation distribution functions and how to incorporate them into three-dimensional models of microstructural evolution. Acta Mater 47(9):2661-2668

Passchier CW, Throuw RAJ (1996) Microtectonics. Springer, Berlin

Sage JD (1988) Thermal microfracturing of marble. In: Marinos PG, Koukis GC (eds) Engineering geology of ancient works, monuments and historical sites, vol 2. A. A. Balkema, Rotterdam, pp 1013-1018

Saylor DM, Fridy J, El-Dasher BS, Jung KY, Rollett AD (2004) Statistically representative three-dimensional microstructures based on orthogonal observation sections. Metall Mater Trans A 35A:1969-1979

Saylor DM, Fuller ER, Weiss T (2007) Thermal-elastic response of marble polycrystals: influence of grain orientation configuration. Int J Mat Res (formerly Z. Metallkd.) 98(12):1256-1263

Shelley D (1993) Igneous and metamorphic rocks under the microscope. Chapmann and Hall, London

Siegesmund S, Dürrast H (2011) Physical and mechanical properties of rocks. In: Siegesmund S, Snethlage R (eds) Stone in architecture. Springer, Berlin (in press)

Siegesmund S, Ullemeyer K, Weiss T, Tschegg EK (2000) Physical weathering of marbles caused by anisotropic thermal expansion. Int J Earth Sci 89:170-182

Siegesmund S, Ruedrich J, Koch A (2008) Marble bowing: comparative studies of different public building facades. In: Siegesmund 
S, Snethlage R, Ruedrich J (eds) Monumental future: climate change, air pollution, stone decay and conservation. Environmental geology, vol 56, pp 473-494

Wanner T, Fuller ER, Saylor DM (2010) Homology metrics for microstructure response fields in polycrystals. Acta Mater $58: 102-110$

Weiss T, Oppermann H, Leiss B, Siegesmund S (1999) Microfabric of fresh and weathered marbles: implications and consequences for the reconstruction of the Marmorpalais Potsdam. Z Deut Geol Ges 150:313-332

Weiss T, Siegesmund S, Fuller ER (2002) Thermal stresses and microcracking in calcite and dolomite marbles via finite element modelling. In: Siegesmund S, Weiss T, Vollbrecht A (eds) Natural stone, weathering phenomena, conservation strategies and case studies. Geological Society Special Publication No. 205, The Geological Society of London, London, pp 89-102

Weiss T, Siegesmund S, Fuller ER (2003) Thermal degradation of marble: indications from finite-element modelling. Build Environ 38(9-10):1251-1260
Weiss T, Saylor DM, Fuller ER, Siegesmund S (2004) Prediction of the degradation behaviour of calcareous rocks via finite-element modelling. In: 10th International congress on deterioration and conservation of stone, Stockholm, pp 163-170

Wenk HR, Takeshita T, Bechler E, Erskine BG, Matthies S (1987) Pure shear and simple shear on calcite textures. Comparison of experimental, theoretical and natural data. J Struct Geol 9:731-745

Winkler EM (1994) Stone in architecture: properties, durability, 3rd edn. Springer, Berlin

Zeisig A, Siegesmund S, Weiss T (2002) Thermal expansion and its control on the durability of marbles. In: Siegesmund S, Weiss T, Vollbrecht A (eds) Natural stone, weathering phenomena, conservation strategies and case studies. Geological Society Special Publication No. 205, The Geological Society of London, London, pp 65-80 